\title{
The impact of COVID-19 national lockdown on orthopaedic trauma admissions in the northern part of South Africa: A multicentre review of tertiary- and secondary-level hospital admissions
}

\author{
P A Rachuene, ${ }^{1}$ FC Orth (SA); R R Masipa, ${ }^{2}$ MB ChB; R Dey, ${ }^{3,4}$ PhD; M Msingapantsi, ${ }^{5,6}$ FC Orth (SA); S M Khanyile, ${ }^{1}$ FC Orth (SA); \\ M P Phala, ${ }^{1}$ FC Orth (SA); J K Murila, ${ }^{5,6}$ MB ChB; M T Mariba, ${ }^{1}$ FC Orth (SA) \\ ${ }^{1}$ Department of Orthopaedic Surgery, Dr George Mukhari Academic Hospital and School of Medicine, Sefako Makgatho Health Sciences University, \\ Pretoria, South Africa \\ ${ }^{2}$ Department of Orthopaedic Surgery, Pietersburg Provincial Hospital, Polokwane, South Africa \\ ${ }^{3}$ Division of Orthopaedic Surgery, Department of Surgery, Groote Schuur Hospital, Cape Town, South Africa \\ ${ }^{4}$ Department of Human Biology, Division of Biomedical Engineering, Faculty of Health Sciences, University of Cape Town, South Africa \\ ${ }^{5}$ Department of Orthopaedic Surgery, Job Shimankana Tabane Hospital, Rustenburg, South Africa \\ ${ }^{6}$ Department of Orthopaedics, School of Medicine, Sefako Makgatho Health Sciences University, Satellite Campus, Rustenburg, South Africa
}

Corresponding author: P A Rachuene (archie.pududu@gmail.com)

\begin{abstract}
Background. COVID-19 national lockdown measures in South Africa (SA) have been under scrutiny since they were implemented in March 2020. Currently there are no studies showing the effect of the first lockdown on hospital admissions in the northern provinces of SA. Objectives. To evaluate the impact of national lockdown restrictions on musculoskeletal injury admissions in three hospitals across three provinces (Gauteng, Limpopo and North West).

Methods. In a retrospective review, we compared orthopaedic trauma admissions from 1 April 2020 to 30 June 2020 (during alert level 5 of the national lockdown) with cases admitted during the same period in 2019 (non-lockdown). We reviewed the number of admissions, demographic data and mechanisms of injury in the adult and paediatric population groups.

Results. A total of 449 patients were admitted with musculoskeletal injuries during the lockdown period compared with 664 patients in 2019 , equating to a $32 \%$ reduction in total admissions. While there was an $8 \%$ increase in paediatric admissions during lockdown at Dr George Mukhari Academic Hospital, adult admissions decreased in all centres. More young males were admitted during both lockdown (mean age 39.8 years) and non-lockdown (mean age 41.2 years) periods than females ( $p=0.004)$. There were significant reductions in the number of injuries due to motor vehicle accidents (59\%) and in the number of gunshot wounds (36\%) during lockdown. However, we observed an $11 \%$ rise in injuries related to suicide attempts among adult admissions during the lockdown period.

Conclusions. Lockdown restrictions resulted in a significant reduction in orthopaedic trauma admissions, and were effective in terms of allowing institutions to direct resources to the management of COVID-19 patients. In the light of the increased suicide attempts observed during lockdown, future lockdown regulations should include comprehensive measures to relieve socioeconomic stress.
\end{abstract}

S Afr Med J 2021;111(7):668-673. https://doi.org/10.7196/SAMJ.2021.v111i7.15581

National lockdown measures in response to the outbreak of COVID-19 in South Africa (SA) were introduced on 27 March 2020. The period covered by these restrictions included the Easter holidays, during which, together with the December holidays, there are a large number of traumatic injuries that have to be treated at already burdened SA healthcare institutions. ${ }^{[1]}$ Interprovincial travelling increases during these holiday periods, resulting in a rise in the number of motor vehicle accidents (MVAs) and pedestrian vehicle accidents (PVAs). Trauma is the leading cause of death in people aged $<45$ years globally, with significant numbers observed in developing countries. ${ }^{[2]}$ Road accidents are the commonest cause of traumarelated death in SA, with almost double the global rate. ${ }^{[3]}$ Pretorius and Firth ${ }^{[4]}$ reported that $13.4 \%$ of paediatric orthopaedic trauma admissions at Chris Hani Baragwanath Hospital were secondary to road traffic accidents, in contrast to $7 \%$ reported by Rennie et al. ${ }^{[5]}$ in the UK. Non-fatal injuries secondary to road accidents often result in permanent disability, placing a heavy burden on the healthcare sectors in low-income countries. ${ }^{[6]}$
Lockdown in SA was graded into five levels, with alert level 5, implemented on 27 March, being the most restrictive. Citizens were not allowed to leave their homes unless they were providing essential services or needed to buy food and other goods regarded as essential, and interprovincial travel and the sale of alcohol and its consumption in public spaces were banned. ${ }^{[7,8]}$ The restrictions were relaxed to some extent with migration to level 4 lockdown on 1 May 2020, and were eased further under level 3 on 1 June, when the sale of alcohol was permitted between Monday and Thursday, during daytime only. ${ }^{[0]}$ Navsaria et al. ${ }^{[10]}$ and Waters et al. ${ }^{[11]}$ reported a decline in trauma cases in Cape Town during the hard lockdown period, but we are not aware that the situation has been evaluated in the northern part of SA.

\section{Objectives}

To evaluate the effect of lockdown measures and the alcohol ban on the number of orthopaedic trauma admissions in the major cities across Limpopo, North West and Gauteng provinces during the first wave of coronavirus infections in SA. At the time of writing 
(December 2020), SA was on alert level 3 lockdown but entering a second COVID-19 wave caused by a reportedly more transmissible strain of the SARS-CoV-2 virus. ${ }^{[12]}$

\section{Methods}

A retrospective study design was used, as it allowed for comparison of the trauma admission rates during level 5 COVID-19 lockdown in 2020 with those during the same period in 2019 (non-lockdown). The study hospitals were two tertiary and one secondary hospital, namely Dr George Mukhari Academic Hospital (DGMAH) in Pretoria, Pietersburg Provincial Hospital (PPH) in Polokwane, and Job Shimankana Tabane Hospital (JSTH) in Rustenburg. DGMAH is a tertiary-level centre and receives referrals from the northern parts of Gauteng and large parts of Limpopo and North West. These regions are largely rural, with poor infrastructure and limited access to healthcare. The other two hospitals are the referral centres in their regions, and they in turn refer complex non-trauma and trauma cases to DGMAH. A data-collection tool designed specifically for this study was used to gather information from the records of the hospitals. Data were collected on adult and paediatric patients with musculoskeletal trauma, including spinal injuries, seen at emergency departments of the hospitals and admitted to the orthopaedic units. We reviewed data from 1 April to 30 June 2020, i.e. during level 5 of the national lockdown, and compared them with admissions to these units during 1 April - 30 June 2019. Medical records of each patient were retrieved and assessed for demographic data, mechanism of injury and type of injury. All patients with trauma-related injury admitted to the orthopaedic units at the participating centres were included in the study. Patients seen at emergency and outpatient departments but not admitted were excluded. Records with incomplete data entry points were also not considered for inclusion.

Patients were first grouped based on the centre to which they were admitted. Within each centre, patients were then grouped into categories of adult and paediatric ( 0 - 13 years), based on the age of the patient.

The mechanisms of injury were categorised into groups described in Table 1. Multiple mechanism categories were grouped under one category to make analysis of the mechanism of injury easier. A $\chi^{2}$ test for independence was performed on the mechanism of injury data captured from 2019 and 2020 to evaluate the effect of lockdown on the mechanisms. Continuous variables obtained for the patients in 2019 and 2020 were compared using the independent-samples Mann-Whitney $U$-test to find any significant differences. All the statistical analyses were performed using SPSS version 26 (IBM, USA), and the cut-off for significance was set at $p<0.05$.

Ethical clearance was obtained from the Sefako Makgatho Health Sciences University Human Research Ethics Committee prior to commencement of the study (ref. no. SMUREC/ M/114/2020:IR).

\section{Results}

A total of 449 patients with musculoskeletal injuries were admitted to the study centres during 1 April - 30 June 2020, i.e. during the national lockdown, compared with 664 patients during the same period in 2019, equating to a $32.4 \%$ reduction in total admissions (Fig. 1). During both years (2019 and 2020) more patients were admitted to DGMAH (64\% and $86 \%$, respectively) than to $\mathrm{PPH}$ in Polokwane (21\% and $8 \%$ ) and JSTH in Rustenburg (15\% and 6\%). More males than females were admitted (75\% v. $25 \%$ of cases). Over both years, paediatric trauma accounted for $28 \%$ of cases v. $72 \%$ for adult trauma. In 2019, paediatric trauma accounted for $24 \%$ of cases v. $76 \%$ for adult trauma, and in 2020 for $32 \%$ of cases v. $68 \%$, i.e. an increase in paediatric trauma cases was noted during the lockdown period (Fig. 5). The average age of adult patients admitted with musculoskeletal injuries in 2019 was 41.2 years, while that in 2020 was 39.8 years $(p=0.004)$. Paediatric patients were slightly older in 2019, with an average age of 11 years v. 10 years in $2020(p=0.036)$. The biggest age variation for adult patients was observed at JSTH, and for paediatric patients at $\mathrm{PPH}$.

Falls were the most common mechanism of injury in both paediatric and adult cases. These included cases of falling from a standing position, falling during strenuous activity, and falling from a height. Injuries due to MVAs were the second most common type of injury, followed by assault injuries. Falls remained the most common cause of injury in 2020 , followed by MVAs. There was a reduction in the number of injuries suffered by adults in 2020, except for domestic injuries and suicide attempts (Fig. 2). More females than males suffered domestic injuries (Fig. 3).

\begin{tabular}{|c|c|}
\hline Mechanism group & Description \\
\hline Falls & $\begin{array}{l}\text { Any kind of fall, including fall on an outstretched hand, fall from a tree, fall on stairs, slip and fall, and } \\
\text { trivial fall }\end{array}$ \\
\hline Injured by falling object & Patient injured by heavy object/s falling on them (e.g. a wall) \\
\hline Motor vehicle accident & $\begin{array}{l}\text { Patient involved in a motorbike, car or any other motor vehicle accident, including falling from a moving } \\
\text { vehicle }\end{array}$ \\
\hline Gunshot injuries/wounds & Any case of musculoskeletal injury to a limb or the spine resulting from a bullet wound \\
\hline Assault & $\begin{array}{l}\text { Musculoskeletal injury to a limb or the spine during assaults (e.g. fights), mob violence, punching a wall or } \\
\text { domestic violence, including stab wounds and human bites }\end{array}$ \\
\hline Sports injuries & Any sports-related incident leading to musculoskeletal injury to a limb or the spine \\
\hline Pedestrian vehicle accidents & $\begin{array}{l}\text { Musculoskeletal injury to a limb or the spine suffered by pedestrians on sidewalks, in parking lots, or on } \\
\text { the road }\end{array}$ \\
\hline Miscellaneous & Any injury resulting from unidentified sources, animal bites, drug use, epileptic fits, etc. \\
\hline Occupational injuries & $\begin{array}{l}\text { Any musculoskeletal injury to a limb or the spine reported during incidents at work caused by machines, } \\
\text { sharp objects, etc. while on duty }\end{array}$ \\
\hline Suicide attempts & $\begin{array}{l}\text { Any suicide or parasuicide attempt leading to musculoskeletal injury to a limb or the spine, such as slashing } \\
\text { a wrist or hanging with a rope }\end{array}$ \\
\hline Domestic injuries & Domestic activities (excluding violent assault) leading to musculoskeletal injury to a limb or the spine \\
\hline
\end{tabular}




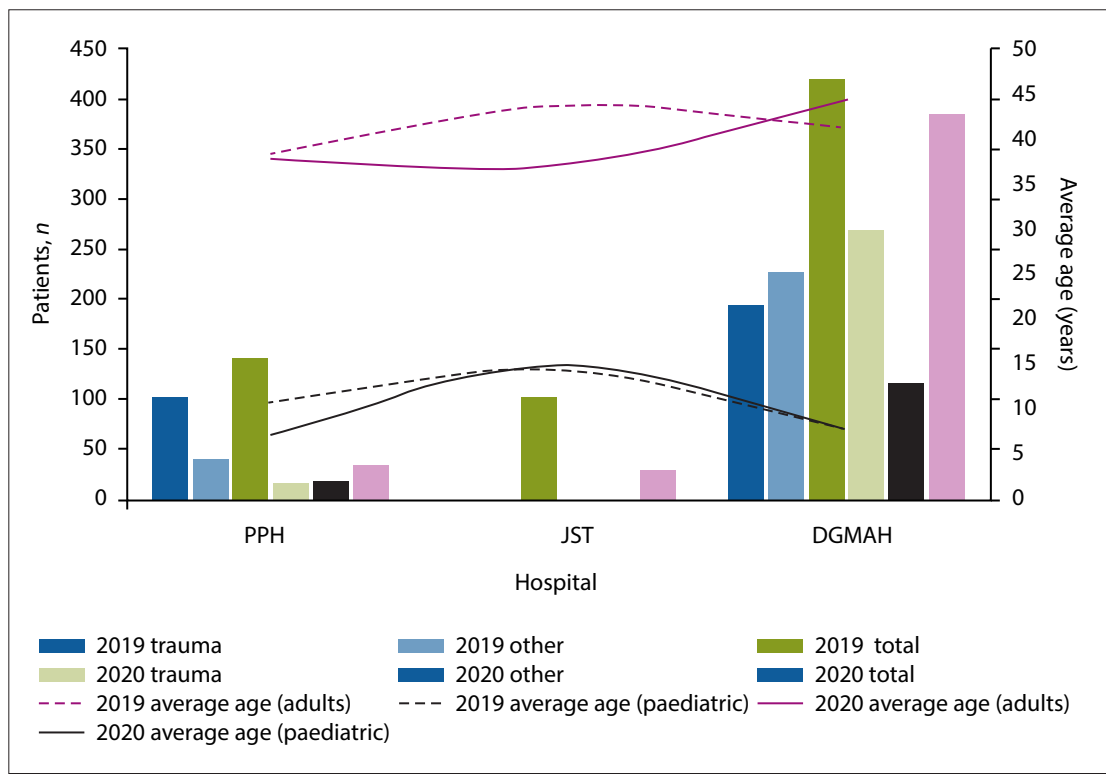

Fig. 1. Summary of cases of musculoskeletal injuries across the three study hospitals. $(P P H=$ Pietersburg Provincial Hospital; JSTH $=$ Job Shimankana Tabane Hospital; DGMAH $=D r$ George Mukhari Academic Hospital.)

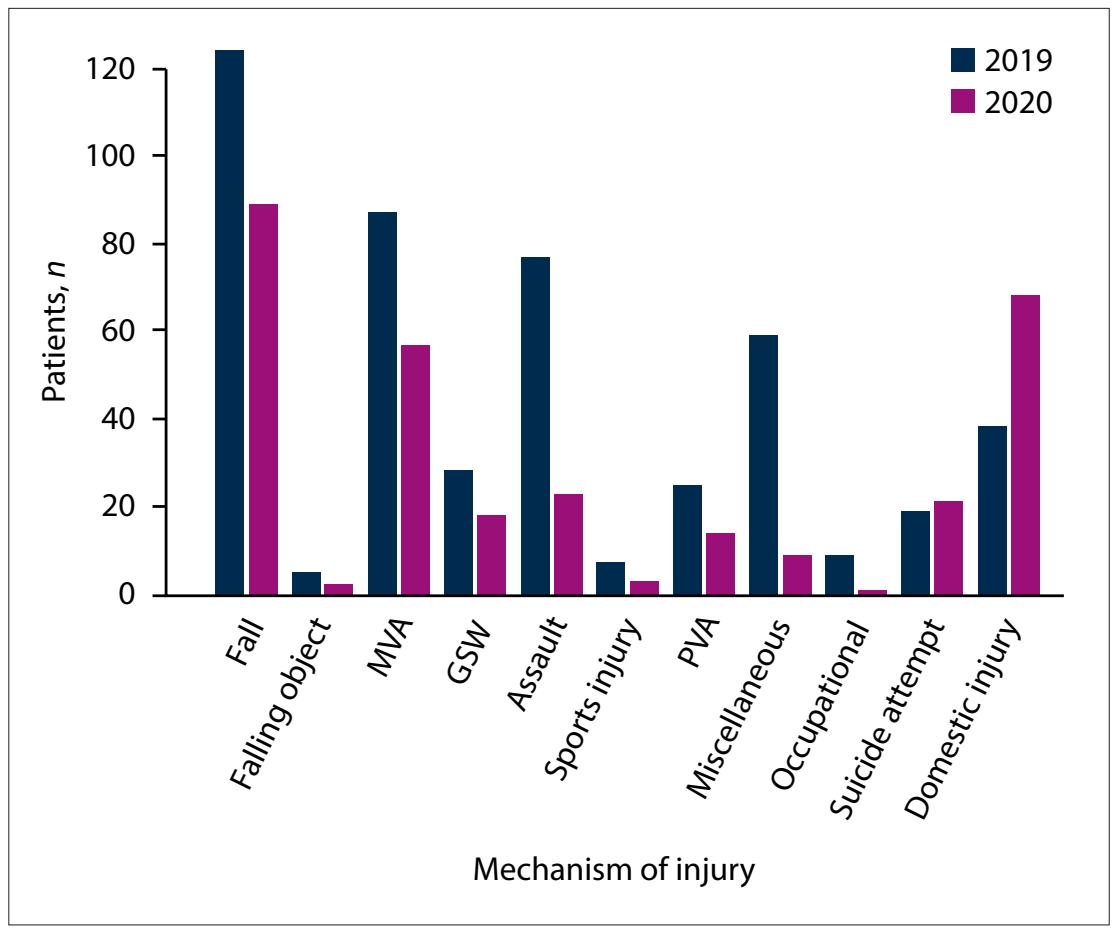

Fig. 2. Comparison of mechanisms of injury in adults treated during lockdown (2020) and those treated before lockdown (2019). (MVA = motor vehicle accident; $G S W=$ gunshot wound; $P V A=$ pedestrian vehicle accident.)

A similar trend was seen in paediatric patients, who mostly suffered from falls, followed by domestic injuries and MVAs. Numbers of both falls and domestic activities leading to musculoskeletal injury were higher in 2020 than in 2019 (Fig. 4). Injuries due to falls, domestic injuries and MVAs were mostly suffered by male rather than female paediatric patients (Fig. 5). adult trauma $(n=57)$ in 2019 compared with $31 \%$ in 2020 .

\section{Gunshot wounds}

No paediatric patient sustained a gunshot wound (GSW) in 2020, while in 2019 there were only 2 . In the adult population, there was a $36 \%$ reduction in GSWs in 2020 $(n=18)$ compared with $2019(n=28)$.

\section{Domestic injuries}

Injuries related to domestic activity increased in both the adult and paediatric populations (by $78 \%$ and $42 \%$, respectively) during the lockdown period. During 2019, 36\% of adult and $41 \%$ of paediatric trauma admissions were for domestic injuries, compared with $64 \%$ and 59\%, respectively, in 2020 .

\section{Suicide attempts}

There was an $11 \%$ increase in adult suicide attempts in 2020 compared with 2019. Paediatric suicide attempts leading to orthopaedic injuries decreased by $80 \%$, i.e. from 5 cases in 2019 to a single case in 2020.

\section{Common assaults}

Injuries from assaults (which included stabs, fights, domestic violence, etc.) in adults decreased by $70 \%$ in 2020 , and in paediatric patients by $89 \%$.

\section{Discussion}

We observed a significant decline in the number of musculoskeletal injuries that required hospital admission across the three provinces from 1 April to 3 June 2020, during the national lockdown period (Fig. 1). Subgroup analysis revealed an overall decline of $12 \%$ in paediatric trauma cases in contrast to a $36 \%$ decline in adult trauma cases. The Easter holidays, notorious for a high number of crashes on SA's national roads, were in early April. The lockdown measures implemented resulted in a significant reduction in patients with musculoskeletal injuries admitted in 2020, even over the Easter weekend, providing a welcome reprieve for the overburdened health sector and allowing institutions to channel resources to the management of COVID-19 cases.

Injuries due to violence also declined during the lockdown period. Gunshot injuries in adults declined by $36 \%$, and assault cases in the same population group by $70 \%$. Numbers of domestic injuries and suicide attempts rose slightly. We think that the former was because people spent more time at home, while the stress of lockdown and its impact on the ability to earn and 


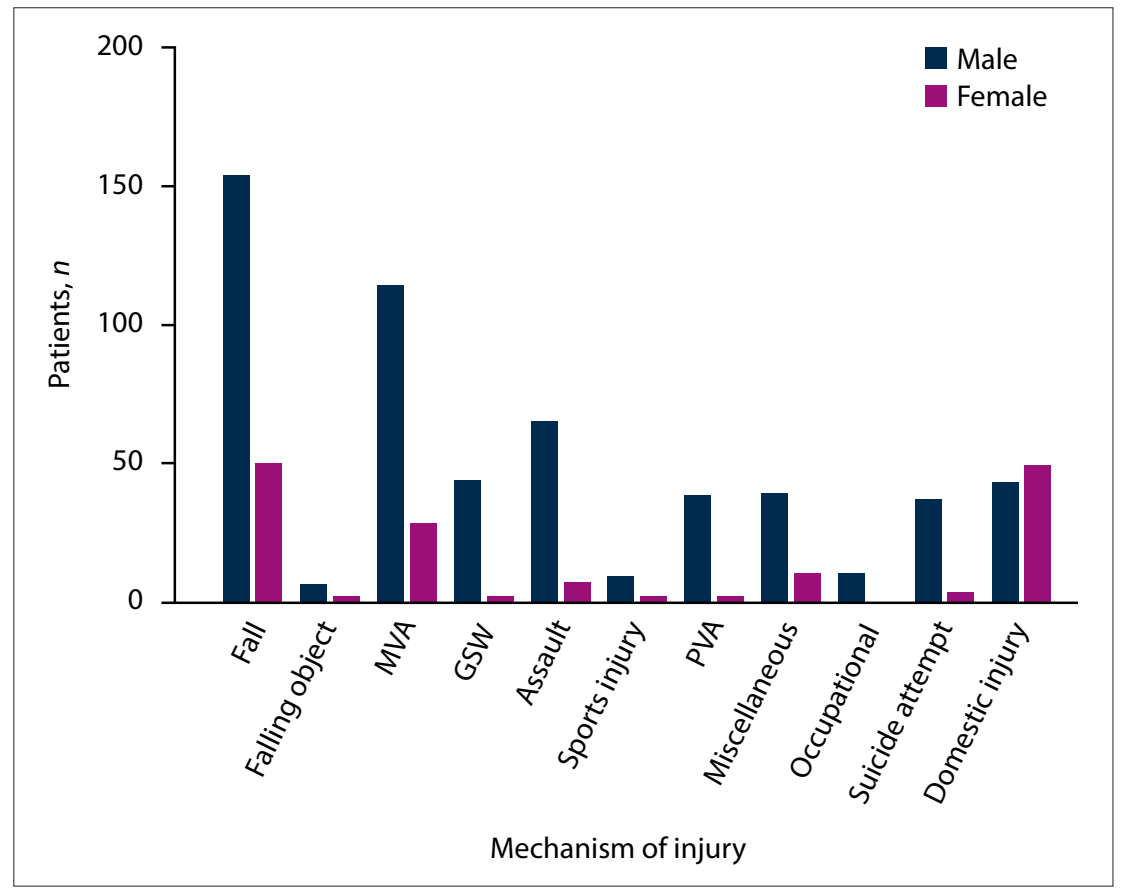

Fig. 3. Mechanisms of injury in relation to gender in adults treated during lockdown (2020) and those treated before lockdown (2019). (MVA = motor vehicle accident; $G S W=$ gunshot wound; $P V A=$ pedestrian vehicle accident.)

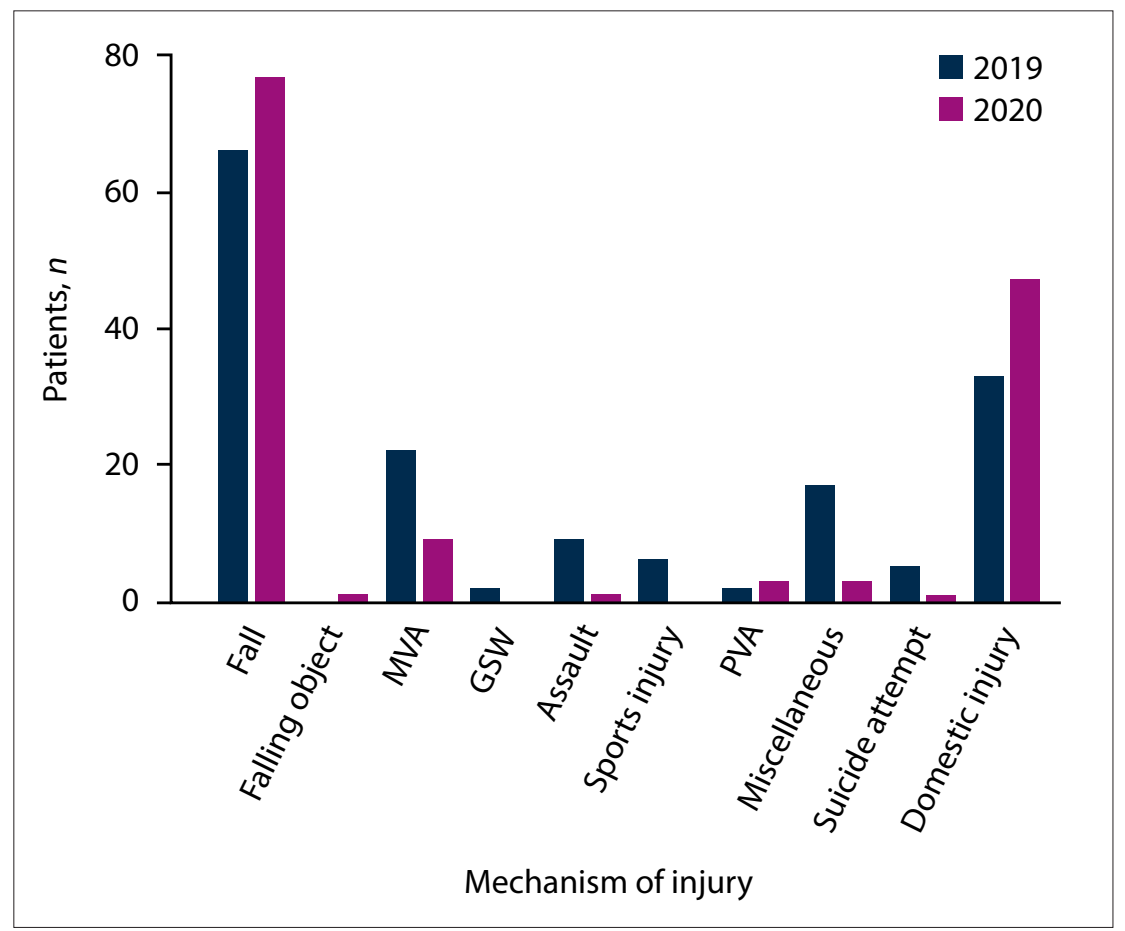

Fig. 4. Comparison of mechanisms of injury in paediatric patients treated during lockdown (2020) and those treated before lockdown (2019). (MVA = motor vehicle accident; $G S W=$ gunshot wound; $P V A=$ pedestrian vehicle accident.)

generate an income may have resulted in an increase in suicide attempts. Social isolation and periods of confinements are in fact established risk factors for parasuicidal behaviours. ${ }^{[13]}$ Caballero-Dominguez et al. ${ }^{[14]}$ reported that $7.6 \%$ of 714 participants were found to be at high risk of suicide during the Columbian lockdown. Crasta et al. ${ }^{[15]}$ found a significant association between 'COVID-19 stressors' and suicidal ideation in a study of 1003 parents that evaluated measures of psychological flexibility during the COVID-19 pandemic.

Similar observations of trauma admissions were reported in other parts of SA. Navsaria et al. ${ }^{[10]}$ reported a $53 \%$ decline in trauma cases at Groote Schuur Hospital, Cape Town, between April and May 2020. They observed significant decreases in numbers of victims of gunshot wounds, stab wounds and road traffic accidents managed at the emergency unit of the hospital during lockdown. Hirschmann et al. ${ }^{[16]}$ reported similar trends at Chris Hani Baragwanath Academic Hospital in Johannesburg, with a $45.3 \%$ reduction in daily admissions during level 5 national lockdown, from an average of 15 to 6.8 cases per day. ${ }^{[16]}$ Reuter et al. ${ }^{[17]}$ observed a reduction in trauma cases treated at an emergency unit in the Garden Route area, coinciding with the alcohol ban during level 5 lockdown.

International experience is very similar to the SA observations. Hampton et al. ${ }^{[18]}$ reported a 53\% reduction in orthopaedic trauma admissions over a 2 -week period during early lockdown in the UK, compared with the same period during the previous year. In another UK study, Jenkins ${ }^{[19]}$ found a $27.3 \%$ reduction in number of trauma operations during lockdown period. In Asia, Sahu et al. ${ }^{[20]}$ noted a decline in number of orthopaedic injuries in an Indian multicentre study. We observed the biggest decline in sports-related injuries compared with other injury mechanisms. Although we observed a reduction of $12 \%$ in overall paediatric admissions across all three centres during lockdown, DGMAH recorded an increase of $8 \%$ in paediatric injuries during this period. DGMAH is the biggest of the three centres we reviewed. We think that these injuries increased because children had more time than usual to play and also needed to be creative with their play activities, as they did not have access to play areas such as those at schools and parks. Future studies should investigate children's activities during strict lockdown periods that prohibit them from attending school and outdoor play areas.

While we made every attempt to optimise treatment in our trauma patients who also had COVID-19 infection, patients with fractures and COVID-19 are at high risk of mortality, and those with asymptomatic infection may become symptomatic following a musculoskeletal injury. Mi et al. ${ }^{[21]}$ reported a $40 \%$ mortality rate in 10 COVID-19-positive patients (age range 34 87 years) who underwent emergency surgery for fractures. In Italy, Catellani et al. ${ }^{[22]}$ reported 


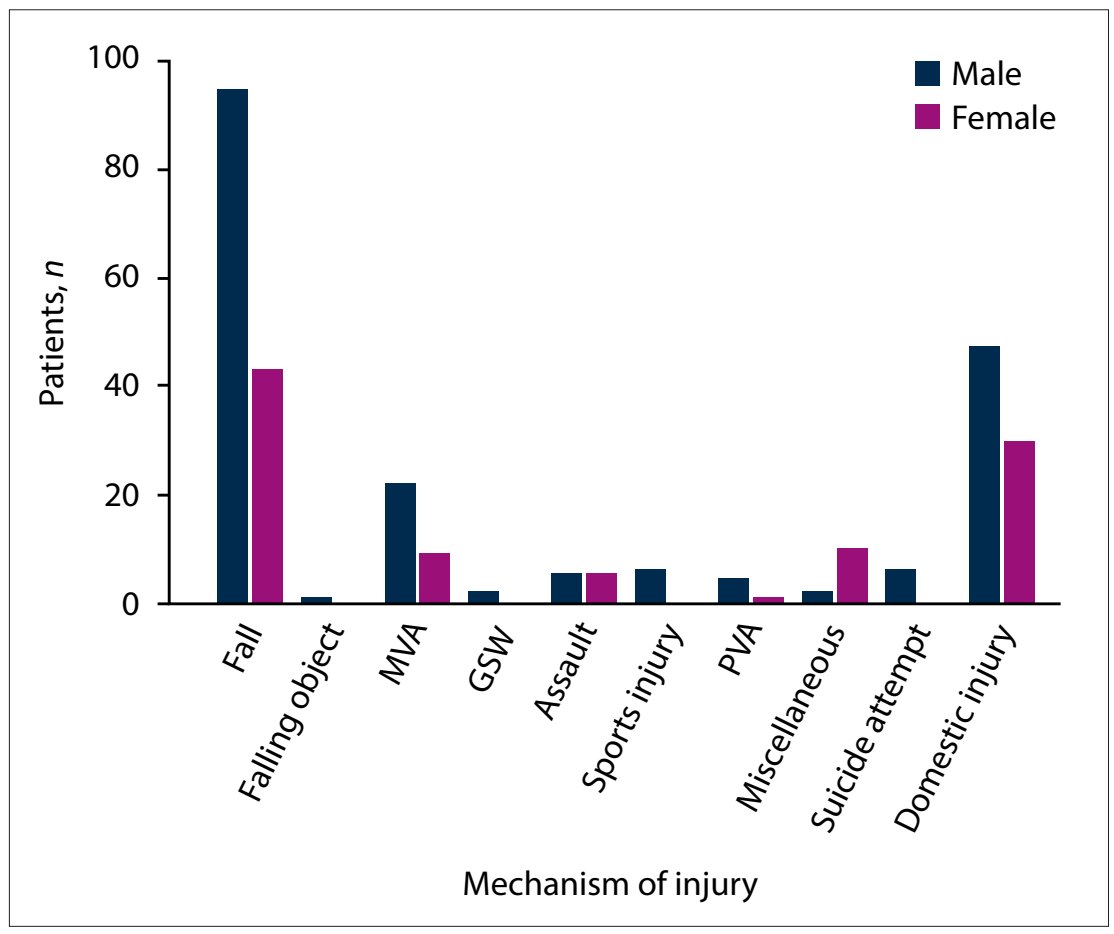

Fig. 5. Mechanisms of injury in relation to gender in paediatric patients treated during lockdown (2020) and those treated before lockdown (2019). (MVA = motor vehicle accident; GSW = gunshot wound; $P V A=$ pedestrian vehicle accident.)

a $62.5 \%$ mortality rate in elderly COVID-19positive patients who underwent surgery for hip fractures. All developed respiratory symptoms following these injuries. Advanced age and the presence of medical comorbidities were risk factors for mortality in this series. We did not evaluate the outcomes of the musculoskeletal injuries or the impact of COVID-19 in our patients. Future studies should assess the effect of the infection, to ensure safe management of musculoskeletal injuries during COVID-19 peaks.

The writing of this article coincided with the resurgence of the COVID-19 pandemic in SA, which also included the holiday season. On 28 December 2020, the President declared the country to be going through the second wave, and announced that lockdown would move back to alert level 3. Prior to implementation of these restrictions, hospitals throughout the country were experiencing a dual burden from both new COVID-19 cases and traumatic injuries. ${ }^{[23]}$ Within days of the implementation of level 3 lockdown, Chris Hani Baragwanath Academic Hospital reported zero trauma admissions on New Year's Eve - for the first time in the history of the hospital. ${ }^{[24]}$

\section{Study limitations and strengths}

The study was limited by the fact that it was conducted over a short period of time. The retrospective study design can be considered both a strength and a weakness. It was less time consuming and very cost effective to conduct, but the cohort size was reduced by the number of data sets with missing data entry points that could not be included. The fact that it was a multicentre review that included three institutions from different geographical areas should increase the generalisability of the findings to most parts of the country, where we can expect similar trends.

\section{Conclusions}

The SA government's efforts to reduce the burden of trauma on healthcare establishments and divert resources to deal with the COVID-19 pandemic were effective. Lockdown measures restricted people to their homes, and the sale of alcohol was prohibited. As a result, road crashes and cases of assault were reduced. However, we observed an increase in the incidences of domestic injuries and suicide attempts. As we fought the second wave of the pandemic at the time of writing, and with the probability of a third wave, lockdown measures were and are crucial for relieving hospitals and allowing healthcare practitioners to provide undivided attention to critically ill COVID-19 patients.
Declaration. None.

Acknowledgements. Andronica Masipa contributed to language and grammar editing and corrections.

Author contributions. PAR: conceptualising the research, preparation of the manuscript, final approval of the version to be published. RRM: data collection, data compilation, preparation of the manuscript and critical editing of the article. RD: data analysis and interpretation, critical revision of the article, final approval of the version to be published. MM: data compilation, critical editing and revision of the article. SMK: data collection, data compilation and manuscript editing. MPP: data collection, data compilation and manuscript editing. JKM: data collection, data compilation and manuscript editing. MTM: senior guidance, critical revision of the article and final approval of the version to be published.

Funding. None.

Conflicts of interest. None.

1. Lewis $C$, Wood D. Interpersonal violence as a major contributor towards the skewed burden of trauma in KwaZulu-Natal, South Africa. S Afr Med J 2015;105(10):827-830. https://doi. org/10.7196/SAMJnew. 8380

2. Miclau T, Hoogervorst P, Shearer DW, et al. Current status of musculoskeletal trauma care systems worldwide. J Orth Trauma 2018;32(10):S64-S70. https://doi.org/10.1097/ BOT.0000000000001301

3. Norman R, Matzopoulos R, Groenewald P, Bradshaw D The high burden of injuries in South Africa. Bull World The he bull World Health Organ 2007;85(9):649-732. https://www.who.int/bulletin/ volumes/85/9/06-037184/en/ (accessed 24 January 2021).

. Pretorius CJ, Firth GB. Road traffic accidents and orthopaedic injuries in children. SA Orthop J 2010;9(Spring):65-68. http://www.scielo.org. za/pdf/saoj/v9n3/v9n3al3.pdf (accessed 15 February 2021).

5. Rennie L, Court-Brown CM, Mok JYQ, Beattie TF. The epidemiology of fractures in children. Injury 2007;38(8):913922. https://doi.org/10.1016/j.injury.2007.01.036

6. Yusuf M, Gebrye T, Fatoye F. Burden of musculoskeletal related disorders resulting from non-fatal road traffic collisions in Africa: A protocol of a systematic review BMJ Open 2019;9(10):1-3. https://doi.org/10.1136 bmjopen-2019-032687

7. South African Government. Regulations and Guidelines Coronavirus COVID-19. https://www.gov.za/covid-19/resources/ regulations-and-guidelines-coronavirus-covid-19 (accessed 24 May 2021).

8. SABC. INFOGRAPHIC | South Africa's lockdown level 5, 4 3, 2 and 1. 1 May 2020. https://www.sabcnews.com/sabcnews/ infographic-south-africas-lockdown-level-5432-and-1/

9. Lekabe T. Level 3: All the lockdown regulation changes come 1 June. Eyewitness News, 2020. https://ewn.co.za/2020/05/24/ level-3-all-the-lockdown-regulation-changes-come-1-june (accessed 24 May 2021).

10. Navsaria PH, Nicol AJ, Parry CDH, Matzopoulos R, Maqungo S, Gaudin R. The effect of lockdown on intentional and non-intentional injury during the COVID-19 pandemic in Cape Town, South Africa: A preliminary report. S Afr Med J 2021;111(2):110-113. https://doi.org/10.7196/SAMJ.2021. v111i2.15318

11. Waters R, Dey R, Laubscher M, et al. Drastic reduction of orthopaedic services at an urban tertiary hospital in South orthopaedic services at an urban tertiary hospital in South
Africa during COVID-19: Lessons for the future response to the pandemic. S Afr Med J 2021;111(3):240-244. https://doi. the pandemic. S Afr Med J 2021;111

12. Rubin EJ, Baden LR, Abdool Karim SS, Morrissey S. Audio Rubin EJ, Baden LR, Abdool Karim SS, Morrissey S. Audio
Interview: Covid-19 in South Africa and a new SARS-CoV-2 variant. N Engl J Med 2021;384(2):el4. https://doi.org/10.1056/ NEJMe2 100736

13. Calati R, Ferrari C, Brittner M, et al. Suicidal thoughts and behaviors and social isolation: A narrative review of the literature. J Affect Disord 2019;245:653-667. https://doi. org/10.1016/j.jad.2018.11.022 
14. Caballero-Domínguez CC, Jiménez-Villamizar MP, Campo-Arias A. Suicide risk during the lockdown due to coronavirus disease (COVID-19) in Colombia. Death Stud 2020 (epub 26 June). https://doi.or g/10.1080/07481187.2020.1784312

15. Crasta D, Daks JS, Rogge RD. Modeling suicide risk among parents during the COVID-19 pandemic: Psychological inflexibility exacerbates the impact of COVID-19 stressors on interpersonal risk factor for suicide. J Context Behav Sci 2020;18:117-127. https://doi.org/10.1016/j.jcbs.2020.09.003

16. Hirschmann A, Pillay T, Fang KW, Ramokgopa MT, Frey C. DEFCON 5: The Chris Hani Baragwanath Academic Hospital orthopaedic department's COVID-19 proactive action plan. SA Orthop 2020;19(3):138-144. https://doi.org/10.17159/2309-8309/2020/v19n3a2

17. Reuter H, Jenkins LS, de Jong M, Reid S, Vonk M. Prohibiting alcohol sales during the coronavirus disease 2019 pandemic has positive effects on health services in South Africa. Afr J Prim Health Care Fam Med 2020;12(1):1-4. https://doi.org/10.4102/phcfm.v12i1.2528

18. Hampton M, Clark M, Baxter I, et al. The effects of a UK lockdown on orthopaedic trauma admission and surgical cases. Bone Joint Open 2020:1(5):137-143. https///doi.org/10.1302/2046-3758.15.BJO2020-0028.R1

19. Jenkins P. The early effect of COVID-19 on trauma and elective orthopaedic surgery. British Orthopaedic Association, 17 April 2020. https://www.boa.ac.uk/policy-engagement/journal-ofOrthopaedic Association, 17 April 2020. https://www.boa.ac.uk/policy-engagement/journal-of-
trauma-orthopaedics/journal-of-trauma-orthopaedics-and-coronavirus/the-early-effect-of-covidtrauma-orthopaedics/journal-of-trauma-orthopaedics-
20. Sahu D, Agrawal T, Rathod V, Bagaria V. Impact of COVID 19 lockdown on orthopaedic surgeons in India: A survey. J Clin Orthop Trauma 2020;11(Suppl 2):S283-S290. https://doi.org/10.1016/j. jot.2020.05.007

21. Mi B, Chen L, Xiong Y, Xue H, Zhou W, Liu G. Characteristics and early prognosis of COVID-19 infection in fracture patients. J Bone Joint Surg Am 2020;102(9):750-758. https://doi.org/10.2106/JBJS.20.00390 22. Catellani F, Coscione A, Usai L, Roscitano C, Fiorentino G. Treatment of proximal femoral fragility fractures in patients with COVID-19 during the SARS-CoV-2 outbreak in Northern Italy. J Bone Joint Surg 2020;102(12):e58. https://doi.org/10.2106/JBJS.20.00617

23. Winde A. 'COVID-19 is not on holiday. We all must take extra precautions'. Western Cape Government Covid-19 Response, News, 10 December 2020. https://coronavirus.westerncape.gov.za/news/covid-19not-holiday-we-all-must-take-extra-precautions (accessed 27 January 2021).

24. Mitchley A. Historic first: Chris Hani Baragwanath Hospital trauma unit empty on New Year's Eve. News24, 1 January 2021. https://www.news24.com/news24/southafrica/news/watch-historic-first-chrishani-baragwanath-hospital-trauma-unit-empty-on-new-years-eve-20210101 (accessed 7 January 2021)

Accepted 22 February 2021. 